\title{
PATTERN OF MAMMOGRAPHIC FINDINGS AMONG FEMALES REFERRED FOR MAMMOGRAPHY AT TERTIARY CARE CENTRE IN IGIMS, PATNA
}

\author{
Amit Kumar1, Sanjay K. Suman², Umakant Prasad³, Vinod Kumar', Manisha Kumari ${ }^{5}$ \\ ${ }^{1}$ Assistant Professor, Department of Radiodiagnosis, IGIMS, Patna. \\ ${ }^{2}$ Professor and HOD, Department of Radiodiagnosis, IGIMS, Patna. \\ ${ }^{3}$ Assistant Professor, Department of Radiodiagnosis, IGIMS, Patna. \\ ${ }^{4}$ Assistant Professor, Department of Radiodiagnosis, IGIMS, Patna. \\ ${ }^{5}$ Senior Resident, Department of Radiodiagnosis, IGIMS, Patna.
}

\begin{abstract}
BACKGROUND
ABSTRACT

Breast diseases and symptomatology are frequent complaints among female patients seeking consultation in our institute, coming from different parts of Bihar. Most important concern of ours is to segregate cancerous appearing lesions with benign or normal findings. Standard imaging technique used for breast are x-ray mammography, high-resolution sonography and magnetic resonance imaging. Mammography, whether screening or diagnostic is established and accurate first line modality for breast diseases and early detection of breast malignancy.

The objective of this study is to document the pattern of mammographic findings in females advised for mammography (Screening and Diagnostic).
\end{abstract}

\section{MATERIALS AND METHODS}

Female with symptoms of pain in the breast, palpable or non-palpable lumps, nipple discharge or others referred for mammography were included in the study at Department of Radiodiagnosis, IGIMS, Patna from July 2015 to June 2017 . A total of 192 female patients were included in this study. Two standard views (craniocaudal and mediolateral oblique) were used for both breasts. Relevant parameters of patients like age, presenting complaints, indications and mammographic findings were recorded and evaluated.

\section{RESULTS}

A total of 192 patients in this study with age range of $24-75$ years. Of these, $50.52 \%$ presented with breast pain, $34.37 \%$ had palpable lump, while $4.16 \%$ presented with nipple discharge. Overall, positive mammographic findings were noted in $36.83 \%$ of total screening participants. These were well circumscribed breast opacity (5.45\%), speculated opacity (10.41\%), asymmetric soft tissue density (4.15\%), calcification (4.67\%), nipple retraction (1.04\%), tissue retraction (3.38\%), skin thickening (5.20\%) and axillary nodes $(2.86 \%)$. Mammographic calcification was noted in 18 cases, of these 13 cases (72.22\%) showed microcalcification and 5 cases $(27.77 \%)$ showed various form of macrocalcification.

\section{CONCLUSION}

Normal study, dense glandular breast and speculated mass opacities were the commonest mammographic findings in breast disease in our environment because of inclusion of all patients with or without symptoms. Most of them were found to have malignant breast condition than benign in positive mammographic findings, thus it has high diagnostic yield in the evaluation and management of breast in this environment. Follow-up imaging and minimally invasive image-guided biopsy or cytology may be indicated for further evaluation.

\section{KEYWORDS}

Screening Mammography, Asymptomatic and Symptomatic, Early Breast Cancer, FNAC and Biopsy.

HOW TO CITE THIS ARTICLE: Kumar A, Suman SK, Prasad U, et al. Pattern of mammographic findings among females referred for mammography at tertiary care centre in IGIMS, Patna. J. Evolution Med. Dent. Sci. 2018;7(08):948-954, DOI: $10.14260 /$ jemds/2018/217

\section{BACKGROUND}

Breast diseases and symptoms are frequent complaints among female patients in clinical practice and not uncommon in Indian environment. Globally, breast diseases, especially malignant lesions, are of our major concern, as it produces high morbidity and mortality ${ }^{[1]}$ and also economic burden. In this, screening mammography is essentially accurate

'Financial or Other Competing Interest': None.

Submission 07-01-2018, Peer Review 07-02-2018,

Acceptance 12-02-2018, Published 19-02-2018.

Corresponding Author:

Dr. Sanjay K. Suman,

Professor and HOD,

Department of Radiodiagnosis, IGIMS, Patna.

E-mail: drsksuman69@gmail.com

DOI: $10.14260 /$ jemds/2018/217 modality for breast disease diagnosis and early detection of malignant lesions and greatly helps to reduce the mortality of patient from breast cancer.[2]

Symptoms of breast disease which are persistent for long time and associated with other changes are important concern, not only for patient but for clinician as well, because of possibility of breast cancer.[3] Women commonly presenting with breast symptoms are pain, lump, nipple discharge, increased breast size, nipple retraction, skin change or thickening, skin ulceration and axillary lymph nodes.[4,5] Among them, breast lump and pain are the commonest symptoms and a source of great concern when noted in breast diseases.

Breast imaging is an important and integral part of initial triple assessment of breast technique for evaluation of symptomatic breast disease for complete diagnosis. [6,7] Breast 
imaging, especially mammography (screening and diagnostic) plays an important role in the diagnosis of symptomatic breast (pain, lump, nipple discharge and others).[8] Mammographic findings like parenchymal opacity, tissue traction, microcalcification, skin thickening, bloody nipple discharge and nipple retraction may all be suggestive of breast disease. Linear, branched or cluster of microcalcification seen in mammogram may be an early sign of breast malignancy.[7] Other mammographic changes commonly noted and important are- well circumscribed breast opacity, asymmetric soft tissue opacity and coarse/macrocalcification in symptomatic females.

Radiographically, dense breast poses important limitation in x-ray film mammography, as it is difficult to interpret the changes, whether screening or diagnostic. Breast density is greatly influenced by normal physiological or pathological conditions of body. Physiological conditions influencing the breast density are- age, ethnicity, obesity, parity and stages of menstrual cycle, and mostly there is inverse relationship between patient's age and mammographic breast density. Younger women mainly have dense breasts and mammographically difficult to interpret. Important aspect of mammography, screening and diagnostic, is that it effectively facilitates the detection and evaluation of occult lesions in either or opposite breast. Screening mammography sensitivity for cancer detection ranges from $83 \%-95 \%$ and drops down to nearly half $(30 \%-48 \%)$ in patients with radiographically dense and glandular breast. ${ }^{[9,10]}$ So, in such patients, screening ultrasonography plays an important role in detection of clinically occult benign or malignant lesions in Asian women.[11]

Documentation of the pattern of mammographic findings in women undergoing screening mammography will highlight the prevalence of different breast diseases among the different age groups in symptomatic females presenting in IGIMS, Patna, and other parts of Bihar. The prevalence will guide us for further diagnostic investigation and/or treatment in particular group of patients. Also, predicts the relevance of screening imaging in assessment of breast disease and to create awareness about screening imaging among clinician and patients.[12]

\section{Objective}

To document the pattern of mammographic findings in female patients advised for mammography (Screening and Diagnostic).

\section{MATERIALS AND METHODS}

This study was evidence-based, cross-sectional, prospective study having inclusion of 192 female patients with breast symptoms or none referred to the Radiology Department of IGIMS, Patna for mammography from July 2015 to June 2017. All female patients underwent mammography and data sheet was constructed along with patient's detailed clinical history such as age, family history, past history, breast symptoms and clinician's findings.

Mammography study was done on Siemens Mammomat 3000 machine. Two standard views, craniocaudal and mediolateral oblique, were done for both breasts of all female patients in complete erect posture with relaxed shoulder and both arms by the side of body. For craniocaudal view, the breast to be examined was firmly placed in contact with horizontally placed film holder platform at the level of inframammary crease. After keeping the nipple in profile, proper compression of breast to smoothen the skin and proper collimation, x-ray was passed through the centre of base of breast perpendicular to the film. For mediolateral view, breast was kept in oblique sagittal plane and supported by the film holder in the same plane with patient rotated by $45^{\circ}$. After proper breast compression, nipple in profile and collimation, x-ray was passed through the centre of base of breast. This procedure was repeated for contralateral breast as well. The size of $\mathrm{x}$-ray film was $21 \times 22 \mathrm{~cm}$ used. Mammographic films were evaluated for various findings like density of breast, density, shape and size of mass lesion, mass is circumscribed or speculated, any asymmetric breast density, micro/macrocalcification, nipple retraction, tissue distortion, skin/subcutaneous thickening, pectoralis muscle involvement and axillary node presence.

\section{RESULTS}

In this study, 192 patients were screened during the period from July 2015 to June 2017, referred to the Department of Radiology with age range of $24-75$ years and maximum number of patients were between the age group of $40-49$ years, while the age range of least number of patients were 70 - 79 years.

\begin{tabular}{|lll|}
\hline Age Range (Years) & Number & Percentage (\%) \\
\hline $20-29$ & 14 & 7.29 \\
\hline $30-39$ & 61 & 31.77 \\
\hline $40-49$ & 79 & 41.14 \\
\hline $50-59$ & 25 & 13.02 \\
\hline $60-69$ & 10 & 5.20 \\
$70-79$ & 3 & 1.56 \\
\hline Total & 192 & 100 \\
\hline & Table I. Age frequency distribution of study population \\
\hline
\end{tabular}

Patient's symptoms were presented in Table 2. The major complaint was breast lump, breast pain, nipple discharge, nipple retraction and multiple symptoms in different proportions.

\begin{tabular}{|lcc|}
\hline Svmptoms & Number & Percentage (\%) \\
Breast Lump & 66 & 34.37 \\
Breast Pain & 97 & 50.52 \\
\hline Lump+Pain & 14 & 7.29 \\
\hline Nipple discharge & 8 & 4.16 \\
\hline Pain+Nipple discharge & 3 & 1.56 \\
\hline Lump+Nipple discharge & 2 & 1.04 \\
Pain+Retracted nipple & 1 & 0.52 \\
Lump+Retracted nipple & 1 & 0.52 \\
\hline Total & 192 & 100 \\
\hline \multicolumn{2}{r}{ Table II. Frequency distribution of Breast Symptoms } \\
\hline
\end{tabular}


In the mammography study, most prevalent findings were normal appearing breast and dense glandular parenchyma. Normal appearing breasts where the density of breast is completely fatty or fibrofatty or fibroglandular where no direct or indirect evidence of mass, microcalcification or tissue traction noted. Dense glandular breast is considered when breast is dense throughout. Remaining of the patients presented with single lesion or multiple mammographic findings like circumscribed opacity, speculated opacity, speculated opacity with nipple retraction, tissue traction or microcalcification.

\begin{tabular}{|c|c|c|}
\hline Mammographic Findings & Number & Percentage (\%) \\
\hline Normal Findings & 95 & 49.47 \\
\hline Dense Glandular & 52 & 27.08 \\
\hline Circumscribed Opacity & 11 & 5.7 \\
\hline Asymmetrical Soft Tissue density & 6 & 3.1 \\
\hline Speculated Opacity & 21 & 10.93 \\
\hline Calcification & 11 & 5.7 \\
\hline i)micro-calcification & 8 & 4.16 \\
\hline ii)macro-calcification & 3 & 1.56 \\
\hline Skin Thickening & 10 & 5.20 \\
\hline Nipple Retraction & 2 & 1.04 \\
\hline Axillary Nodes & 3 & 1.56 \\
\hline Tissue Traction & 5 & 2.60 \\
\hline
\end{tabular}

\begin{tabular}{|lcc|}
\hline Mammographic Findings & Number & Percentage (\%) \\
Normal Findings & 95 & 49.47 \\
\hline Dense Glandular & 54 & 28.12 \\
\hline Circumscribed Opacity & 7 & 3.64 \\
\hline Asymmetrical Soft Tissue density & 10 & 5.20 \\
\hline Speculated Opacity & 19 & 9.89 \\
\hline Calcification & 7 & 3.64 \\
\hline i)micro-calcification & 5 & 2.60 \\
\hline ii)macro-calcification & 2 & 1.04 \\
\hline Skin Thickening & 10 & 5.20 \\
\hline Nipple Retraction & 2 & 1.04 \\
\hline Axillary Nodes & 8 & 4.16 \\
\hline Tissue Traction & 8 & 4.16 \\
\hline \multicolumn{1}{|c|}{ Table: IV. Mammographic Findings -.-Left Breast } \\
\hline
\end{tabular}

Mammographic findings of each breast were also classified into different BIRADS grades (Breast Imaging Reporting and Data System) developed by American College of Radiology (ACR). Majority of the patients were graded into BIRADS 0 and BIRADS I and remaining patients were BIRADS II to V. We mostly graded the dense glandular breast into BIRADS 0, because nothing was delineable in these homogeneous to heterogeneous dense breasts and further they were advised for high resolution ultrasonography for any pathology if any.

\begin{tabular}{|lcc|}
\hline BIRADS & RIGHT BREAST & LEFT BREAST \\
GRADE O & 51 & 52 \\
\hline GRADE I & 99 & 103 \\
GRADE II & 5 & 2 \\
GRADE III & 8 & 5 \\
GRADE IV & 16 & 15 \\
GRADE V & 17 & 15 \\
\hline \multicolumn{4}{|c}{ Table V. BIRADS Grading of both Breasts } \\
\hline
\end{tabular}

Provisional diagnosis was made to predict the prevalence of benign, suspicious, malignant or normal condition of breast in screening during the study period.

\begin{tabular}{|lcc|}
\hline Normal & 101.00 & $52.60 \%$ \\
\hline Benign & 10.00 & $5.20 \%$ \\
\hline Suspicious & 15.50 & $8.07 \%$ \\
\hline Malignant & 16.00 & $8.33 \%$ \\
\hline Inconclusive (Dense Breast) & 53.00 & $27.60 \%$ \\
\hline Table VI. Provisional Diagnosis on the basis of Mammography findings for Breasts \\
\hline
\end{tabular}

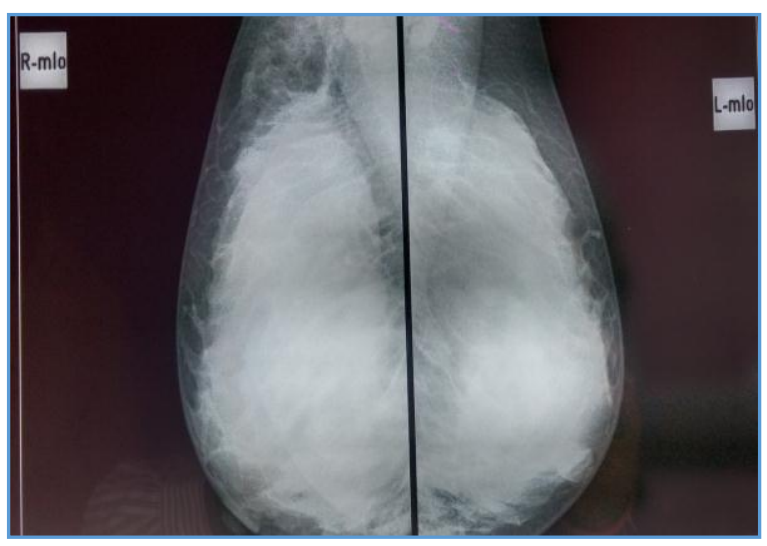

Figure 1. Mammography (Mediolateral Oblique) showing Homogeneous Dense Breast which is the Second Most

Common Findings in our Screening Population and Inconclusive Study suggested further for Alternative High Resolution Ultrasonography (BIRADS 0).

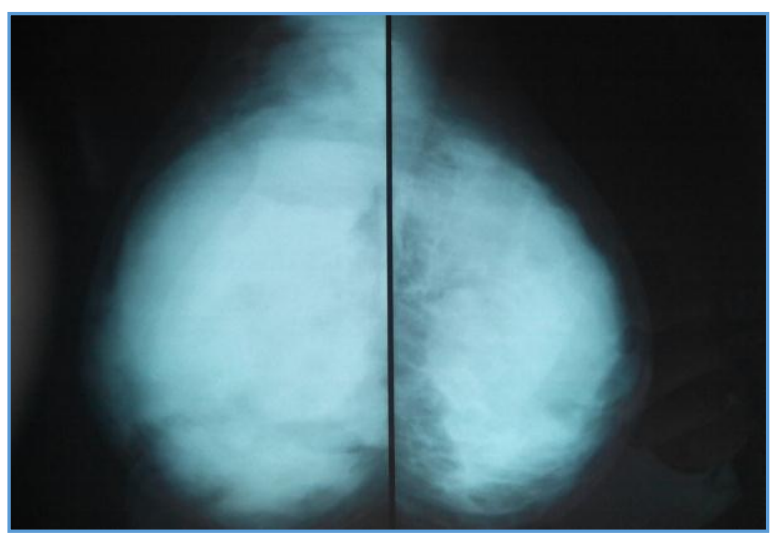

Figure 2. Screening Mammogram (Mediolateral Oblique) showing Homogeneous Dense Breast Parenchyma unable to delineate any Positive Findings (BIRADS 0). 


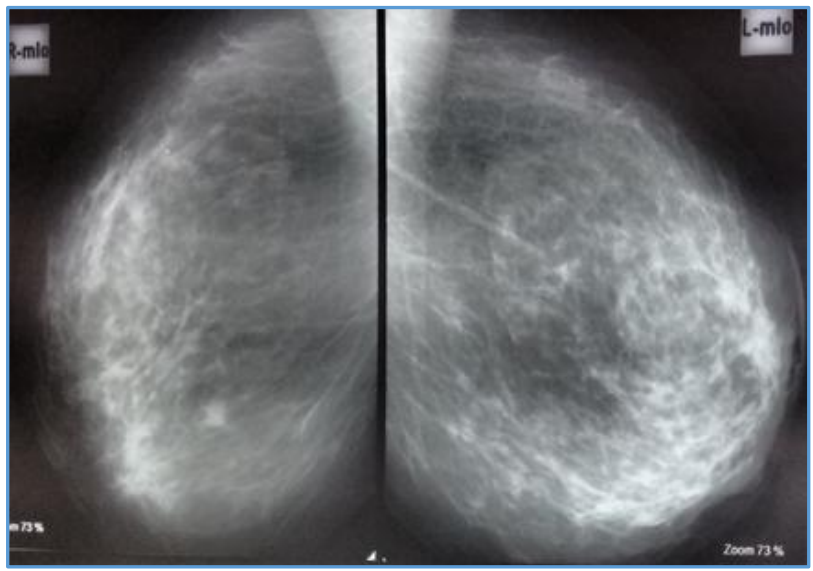

Figure 3. Mammography (Mediolateral Oblique) showing Mixed Density Breast Parenchyma and Screening Study reported as Normal Study, most common findings in our Study Population (BIRADS I)

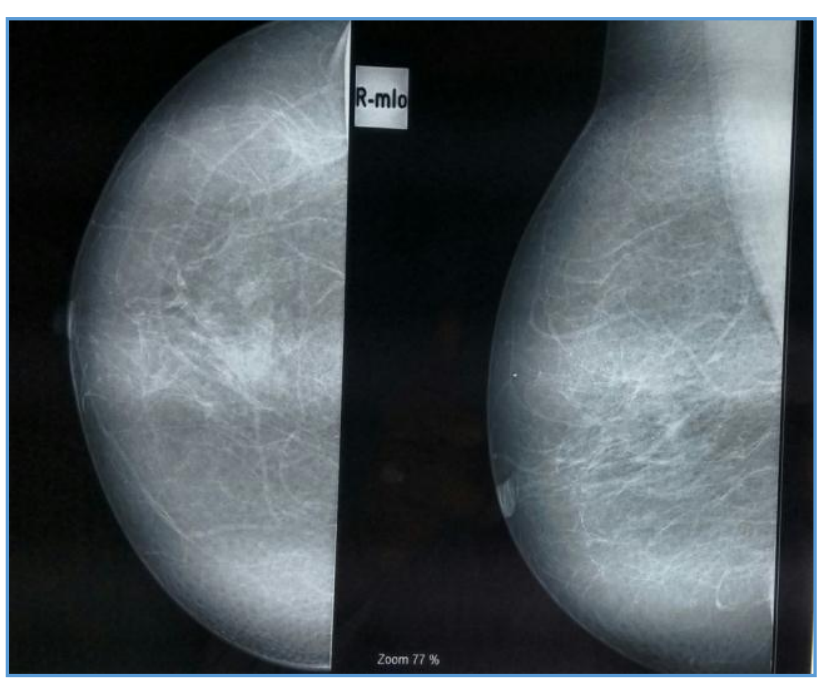

Figure 4. Mammography (Mediolateral Oblique) showing completely Involuted Breast Parenchyma into Fatty Change without any evidence of Positive Findings, most common findings in our Study Population (BIRADS I).

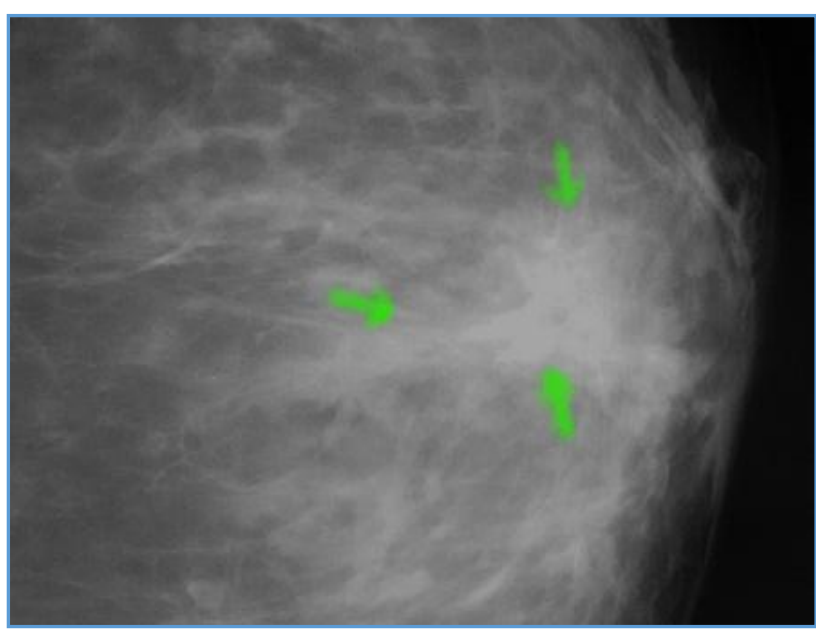

Figure 5. Mammography (Craniocaudal) showing Asymmetric Soft Tissue Density (Green Arrow) in Retroareolar Region without Significant Tissue Traction, Microcalcification or Skin Changes (BIRADS IV).

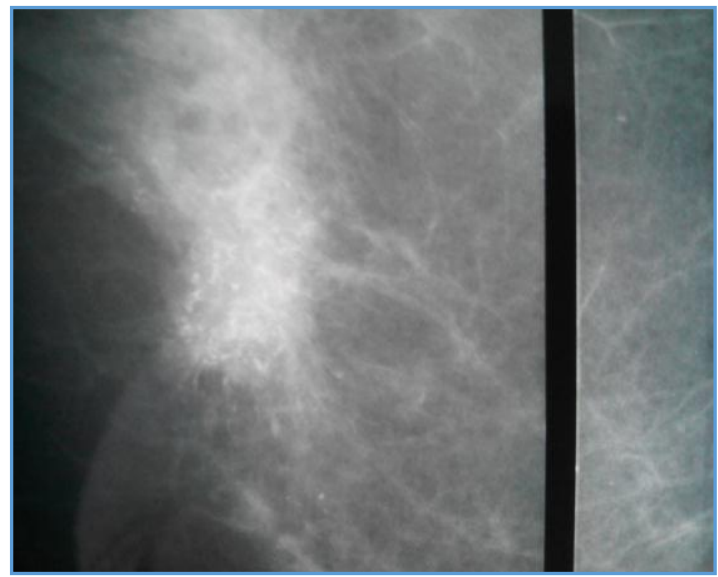

Figure 6. Mammography (Mediolateral Oblique) showing Speculated Opacity in Upper Quadrant with Bread Crumbs Like Microcalcification within Opacity, Tissue Traction and Skin Retraction (BIRADS V).

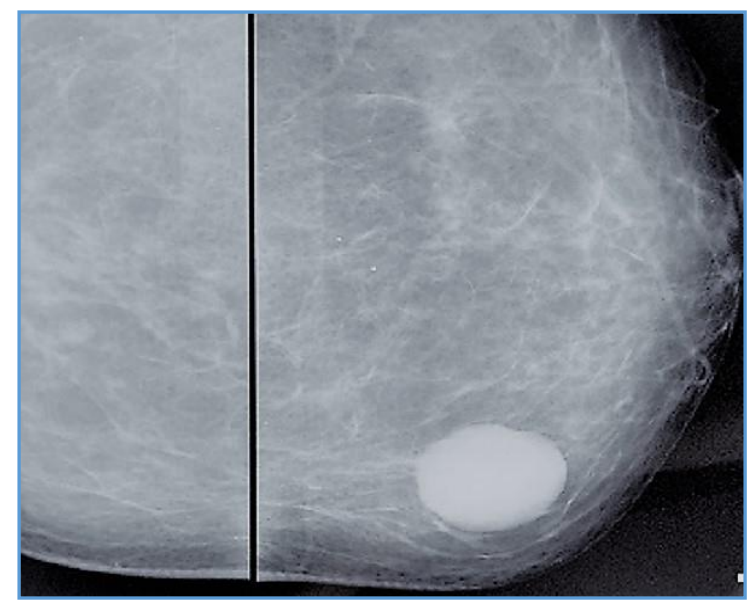

Figure 7. Mammography (Mediolateral Oblique) showing Well-Circumscribed Opacity in Inner Quadrant without any Architectural Distortion, Micro/Macro-Calcification, Trabecular Thickening and Well-Visualised Peripheral

Thin Radiolucent Rim suggestive of Benign Lesion (BIRADS II/III).

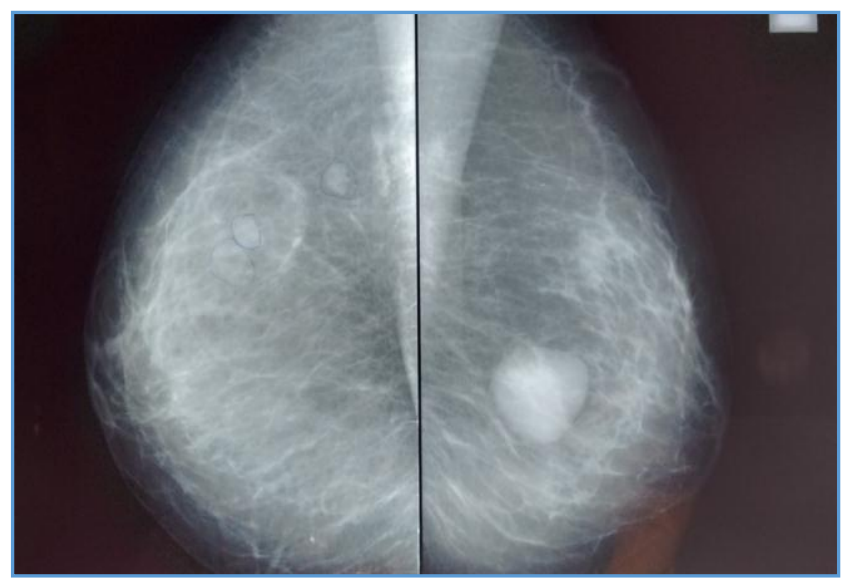

Figure 8. Mammography (Mediolateral Oblique) showing Well-Circumscribed Opacity in both Breasts with defined Peripheral Thin Radiolucent Rim and Bilobulated Border without Tissue Traction and Microcalcification suggestive of Benign Lesion (BIRADS III). 


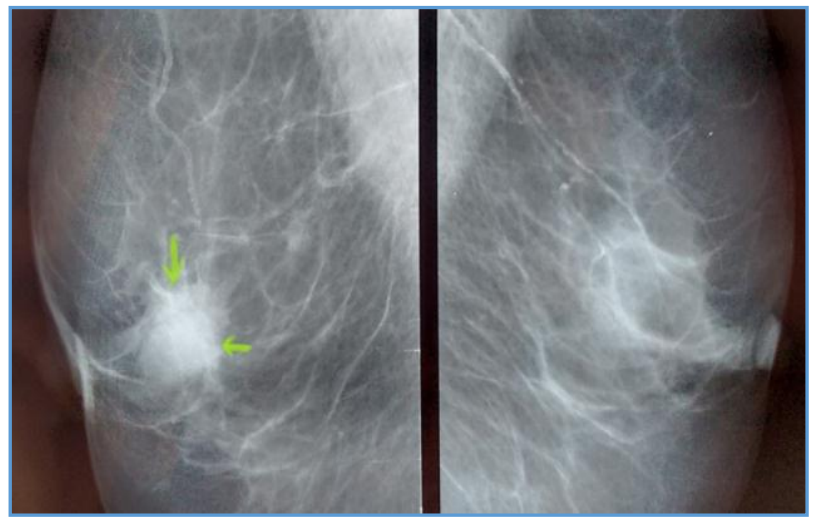

Figure 9. Mammography (Mediolateral Oblique) showing Speculated Opacity (Yellow Arrow) in Retro-areolar Space associated with Tissue Traction and Nipple Retraction in Right Breast (BIRADS V).

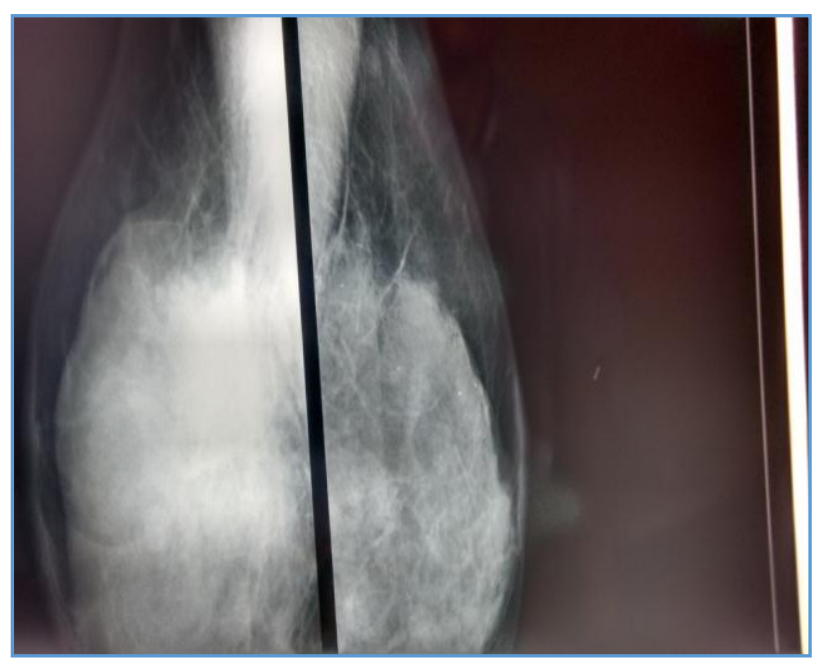

Figure 10. Mammography (Mediolateral Oblique) showing Dense Infiltrating Opacity in most of Right Breast

Parenchyma involving the Pectoralis Muscle (Chest Wall) (BIRADS V).

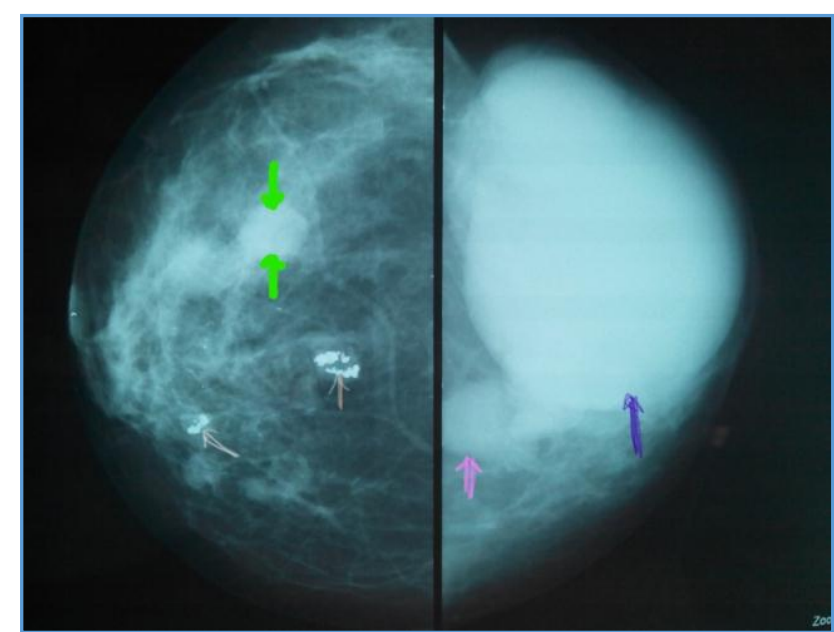

Figure 11. Mammography (Craniocaudal) showing Circumscribed Opacity (Green Arrow) (BIRADS III) and Two Foci of Coarse Calcification (Thin Pink Arrow) (BIRADS II) in Right Breast and Dense Large Circumscribed Opacities (Blue Arrow) in Left Breast (BIRADS III/IV).

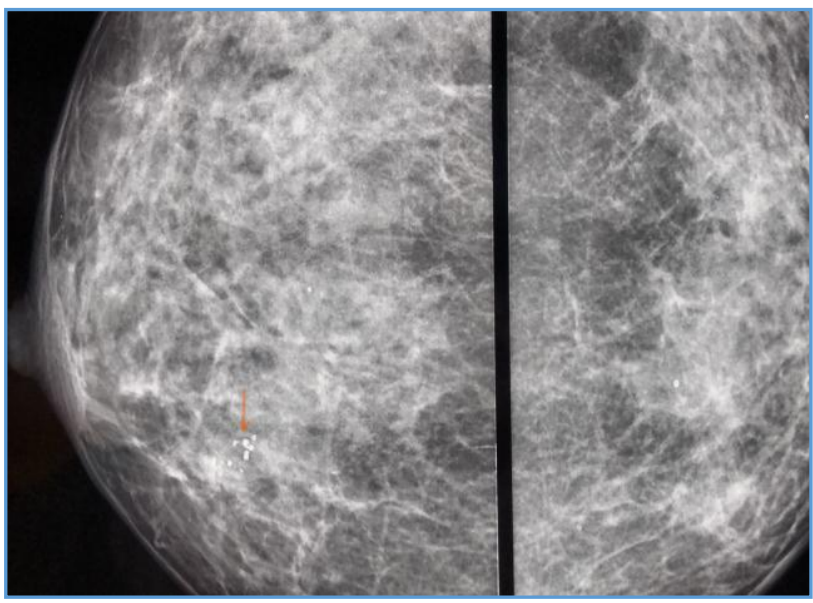

Figure 12. Mammography (Craniocaudal) showing Focal Clump of Microcalcification in Right Breast in Inner Quadrant (Red Arrow) appeared as Suspicious Lesion (BIRADS IV)

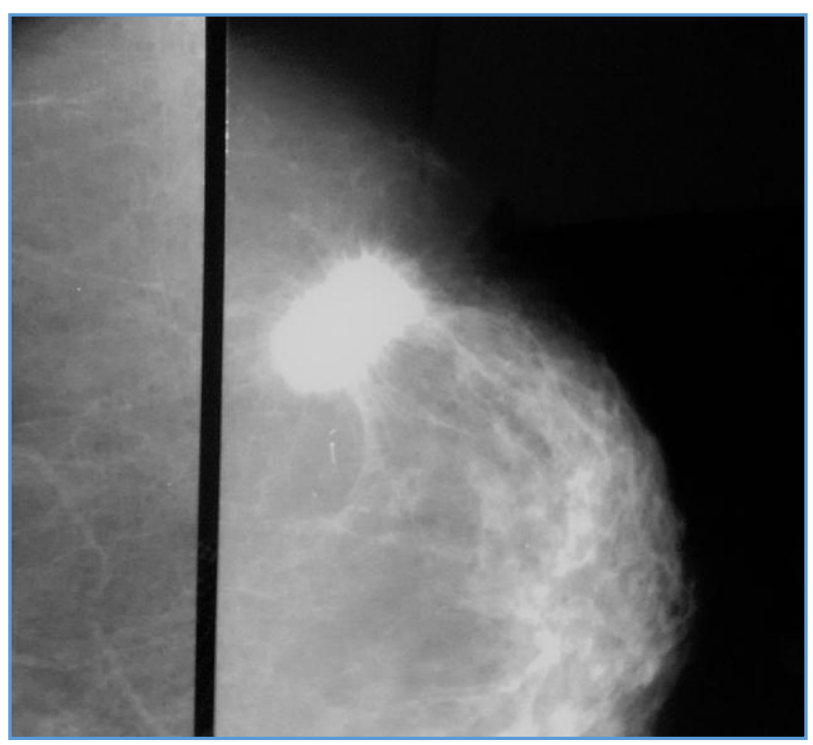

Figure 13. Mammography (Mediolateral Oblique) showing Oval Shape Speculated Opacity with Skin Retraction and Trabecular Thickening in Upper Quadrant, No Microcalcification Seen (BIRADS V).

In this study, $52.60 \%$ patients were reported as normal study, $8.33 \%$ had malignant changes in mammography, $8.07 \%$ patients had suspicious findings and $5.20 \%$ were benign in aetiology. In the remaining patients $(27.60 \%)$, no mammographic conclusion was possible significantly due to dense breast. Most common locations of malignant lesion were- upper outer quadrant and mostly speculated in appearance, while diffuse infiltrative mass lesion were in retro-areolar region associated with retraction of nipple. Total 11 (5.72\%) patients had axillary lymph nodes, in which 4 were associated with malignant lesion and 7 were benign. Other mammographic findings were circumscribed opacity (9.34\%), asymmetric soft tissue density (8.30\%), calcification (9.34\%), skin thickening $(10.40 \%)$, nipple retraction $(2.08 \%)$, tissue traction $(6.76 \%)$ and speculated opacity $(20.82 \%)$.

\section{DISCUSSION}

Our study was evidence-based cross-sectional study of women presenting in IGIMS, Patna, for screening of breast 
symptoms or none. The commonest mammographic finding was- normal study and the next was dense fibroglandular breast. These dense breasts study was not complete and suggested for Ultrasonography for further evaluation. We have various studies in these fields, where these mammographic findings differed.[13]

In this study, mammographic positive findings were noted in $36.83 \%$ of total patients. If we exclude the dense glandular breast parenchymal mammographic findings which were inconclusive, then it constituted the next findings after normal study, thus represented as an important imaging study for breast disease. Screening mammography has high sensitivity $(80.80 \%)$ in the detection of breast diseases, especially in symptomatic women, but this is not corresponding to our study because of inclusion of dense breast in statistical calculation.

Next to the normal mammographic study and dense breast is speculated opacity and circumscribed opacity constituting $10.41 \%$ and $5.45 \%$ respectively suggest high prevalence of malignant findings over suspicious and benign findings in positive mammographic changes and necessitate the importance of mammography in initial screening for breast diseases. Asymmetric soft tissue density noted in $4.15 \%$ women in mammography in almost normal appearing breasts not associated with architectural distortion, Cooper's ligament thickening, skin/subcutaneous thickening or nipple retraction. ${ }^{[7]}$ Such asymmetrical dense changes may be due to focal cluster of normal glandular tissue, benign lesion or may be malignant change with or without calcification. These lesions need further evaluation by ultrasonography or MRI (Magnetic Resonance Imaging). Calcification may be due to benign or malignant pathology seen in $4.67 \%$ of screening mammogram, in which microcalcification was noted in $3.38 \%$ cases and macrocalcification in $1.3 \%$ cases. Microcalcification was related malignant lesions and macrocalcification was with benign lesions. Microcalcifications are important mammographic findings in $25 \%$ of the detected breast carcinoma in screening. [7]

In our study, microcalcifications were noted in 13 breast mammograms, in which 10 cases were associated with mass lesions and 3 cases (around 25\%) showed clumps/spots of microcalcification as sole finding. Such isolated clumps/spots of microcalcification must be evaluated by biopsy, stereotactic or surgical to know the histopathology and diagnosis of lesions.[14] Macrocalcifications are mostly associated with benign lesions like fibroadenoma, fibroadenosis, parasitic and skin related. Other mammographic findings were skin thickening (5.20\%), nipple retraction $(1.04 \%)$ and tissue traction (3.38\%). These were mostly associated with malignant breast lesions, but they can be due to benign lesions as well. Axillary lymph nodes were noted in 11 (2.86\%) women, where only four were related with malignant breast lesions and rest may be normal or benign.

Mammographic findings were also classified into BIRADS grades. It is very easy and convenient method to communicate and help clinicians to understand the reporting idea from different radiologists on mammographic findings about the spectrum of breast disease.[15] In this study $52 \%$ patients were in BIRADS I, $1.82 \%$ in BIRADS II, 3.38\% in BIRADS III, $8.07 \%$ were in BIRADS IV and $8.33 \%$ in BIRADS V. The remaining was graded under BIRADS 0 due to homogeneous to heterogeneous complete dense glandular breast parenchyma. High resolution sonography, FNAC and biopsy were suggested for BIRADS III and IV grades for definitive diagnosis. Dense glandular breasts are important mammographic factor, which impairs or decrease the sensitivity of mammography and cause false negative reporting in $4 \%$ - $12 \%$ of cases.[10]

\section{CONCLUSION}

Normal study, dense glandular breast and speculated mass opacities were the commonest mammographic findings in breast disease in our environment, because of inclusion of all patients having symptoms or not. And most of them were found to have malignant breast condition than benign in positive mammographic findings, thus it has high diagnostic yield in the evaluation and management of breast in this environment. Follow-up imaging and minimally invasive image-guided biopsy or cytology may be indicated for further evaluation.

\section{REFERENCES}

[1] Nggada HA, Gali BM, Bakari AA, et al. The spectrum of female breast diseases among Nigerian population in Sahel climatic zone. J Med \& Med Sci 2011;2(10):1157-61.

[2] Taber L, Vitak B, Chen TH, et al. Swedish two-country trial: impact of mammographic screening on breast cancer mortality during 3 decades. Radiology 2011;260(3):658-63.

[3] Ayoade BA, Tade AO, Salami BA. Clinical features and pattern of presentation of breast diseases in surgical outpatient clinic of a suburban tertiary hospital in South-West Nigeria. Niger J Surg 2012;18(1):13-6.

[4] Adesunkanmi AR, Agbakwuru EA. Benign breast disease at Wesley Guild Hospital, llesha, Nigeria. West Afr J Med 2001;20(2):146-51.

[5] Laver RC, Reed MW, Harrison BJ, et al. The management of women with breast symptoms referred to secondary care clinics in Sheffield: implications for improving local services. Ann R Coll Surg Engl 1999;81(4):242-7.

[6] Madubogu CI, Ukah CO, Chianakwana GU, et al. Diagnostic accuracy of clinical breast examination for breast cancer in patients with palpable breast lump in a middle income country. Orient Journal of Medicine 2013;25(3-4):113-8.

[7] Michell MJ, Lawinski C, Teh W, et al. The breast. In: Sutton D. edr. Textbook of radiology and imaging. Vol. 2. Edinburg, UK: Churchill Livingstone 2003: p. 146475.

[8] American Cancer Society Recommendations for early detection of breast cancer in women without breast symptoms. Breast cancer: early detection. 2013.

[9] Boyd NF, Guo H, Martin LJ, et al. Mammographic density and the risk and detection of breast Cancer. $\mathrm{N}$ Engl J Med 2007;356(3):227-36. 
[10] Mular S, Wordinger S, Mortiz A, et al. Comparison of written reports of mammography, sonography and magnetic resonance mammography for preoperative evaluation of breast lesions, with special emphasis on magnetic resonance mammography. Breast Cancer Res 2001;3(1):55-60.

[11] Akbari A, Razzaghi Z, Homaee F, et al. Parity and breastfeeding are preventive measures against breast cancer in Iranian women. Breast Cancer 2011;18(1)51-5.

[12] Nothacker M, Duda V, Hahn M, et al. Early detection of breast cancer: benefits and risks of supplemental breast ultrasound in asymptomatic women with mammographically dense breast tissue. A systematic review. BMC Cancer 2009; 9:335.
[13] Beerappa JR, Balu S, Kumar NLD, et al. Mammographic and sonomammographic evaluation of breast masses with pathological correlation: a prospective original study. International Journal of Anatomy, Radiology and Surgery 2016;5(3):R09R012.

[14] Anyikam A, Nzegwu MA, Ozumba BC, et al. Benign breast lesions in Eastern Nigeria. Saudi Med J 2008;29(2):241-4.

[15] BIRADS-Mammography. Chapter 2. American College of Radiology. BIRADS Atlas. $5^{\text {th }}$ edn. Reporting System: 2013: p. 121-40. 